\title{
Population Dynamical Stability in Service of Plant Protection Prognosis
}

\author{
L. HUFNAGEL ${ }^{1}$, MÁRTA GAÁL ${ }^{2}$, \\ BRIGITTA ŐSZI ${ }^{3}$ and Z. MÉSZÁROS ${ }^{3}$ \\ ${ }^{1}$ Department of Systematic Zoology and Ecology of the Eötvös Loránd University, \\ Zootaxonomy Research Group of the Hungarian Academy of Sciences, \\ H-1088 Budapest, Puskin u. 3, Hungary \\ ${ }^{2}$ Department of Mathematics and Informatics of the Szent István University, \\ H-1118 Budapest, Villányi út 29-33, Hungary \\ 3 Department of Entomology of the Szent István University, \\ H-1118 Budapest, Ménesi út 44, Hungary
}

\begin{abstract}
The knowledge of the population dynamical characteristics of the pests fundamentally determines the success of the plant protection prognosis. In this paper we examine the possibilities of the utilization of the information about the population dynamical stability that we get from field examination data. We take into account neighbouring data pairs from data series regarding the change of insect density counted at stated intervals. Using these pairs of values - from the tendency of the absolute and relative changes - we can draw conclusion on the stability of the individual density values or on the stability of the whole dynamical pattern.
\end{abstract}

Keywords: Population dynamics, plant protection, stability, new methods.

Preparing plant protection prognoses (Manninger, 1968; Benedek et al., 1969, 1974) usually we can give prediction on the changes of the number of individuals based on the actually measured density values of a given pest and with the knowledge of its biological properties (taking into account other factors, too). The knowledge of the phenology and population dynamics of the species comes from the analysis of previous field examination data. In our study we examine the possibilities of the utilization of the information about the population dynamical stability that lies in these data.

\section{Problems and general considerations}

Many people in many ways use the expression of population dynamical stability and these meanings can refer to very different phenomena depending on the nature and methods of a survey (May, 1973; Maynard Smith and Slatkin, 1973; Juhász-Nagy and Vida, 1978; Vekerdi, 1978; Huffaker, 1984; Den Boer, 1986). It happens frequently that one part of a phenomenon associated with the stability is named with another specific and more exact definition. In a wider sense by stability we mean the static or dynamic continuity (permanence), survival capability and persistency observable in certain circumstances of the value of a measured, measurable or modelable variable (sometimes variables). The index of stability can vary significantly depending on the circumstances even if we have only one variable. Therefore we often make a distinction between local and global stability. Many times even so is insufficient, in this case we must define more precisely the validity 
interval of the index. An index called "stability" can contain information about very different characteristics of the examined variable. According to the differential equations based on population dynamical models the expression of stability is often used as a special (equilibrium) value of a variable to reveal that once the system was moved away from a given value then was left to itself (disturbance, perturbation) whether it can return to its original value and if so how fast could reach it. Depending on the intensity of disturbance this property is called as global or local resilience too, and the frequently applied linear stability analysis refers also to that. We can measure another, fundamentally different phenomenon regarding the question how big intensity needs an external effect to change the actual value or interval of a variable - this we call resistance. The expression of robust we can consider as a generalization of resistance, when we examine in how wide range of a factor (or factors) could be invariable the given value (or interval) of a selected variable.

We can use very well the preceding and many other similar expressions in case of mathematical models or well arranged laboratory experiments, and in this way we can approach (make easier) to understand the phenomena of nature. However in the plant protection prognosis the field examination data have a great importance too, what is more, mainly these form the basis of the practical methods (Benedek et al., 1974; Nowinszky, 1994, 1997). Analyzing the field data (obtained e.g. by light-, color- or sex traps) we can observe states of equilibrium very rarely concerning the measured density values, moreover the interpretation of these is realizable only in special cases. However, in case of the most pests we have very few information, often only hypothesis about the factors which have effect on the abundancy of the population. As a starting point we have only the population dynamical pattern detectable in the time changes of density values. Looking at the curves about the changes in the number of individuals it is inevitable to have a subjective impression about their stability character. If the number of individuals vary rapidly in a wide range without any predictable way, we feel that variable less stable than another with slow, gradual, little by little changes. If we replace this subjective impression with a numeric expression, the information content of the data becomes utilizable. To this we only need to give the actual definition of stability and the method of measurement.

\section{Recommended expressions of stability}

In case of great number of data we can interpret the stability in two ways:

- concerning individual density values or intervals

- concerning the whole density pattern.

Let us consider absolutely stabile that density value in which proximity the population changes with only few individuals by unit of time and relatively stabile where with small rate. For this reason by stability of the individual density values we mean the reciprocal of the size of absolute and relative changes.

The population dynamical pattern we can consider as absolutely stabile when with the increment of the density values the absolute stability values belonging them also increase and instabile when they decrease. The field data are practically always instabile in this respect, so in this case the rate of the decrease and its slowing, constant or accelerating characteristic provides information about the stability. We can consider the 
pattern as relatively stabile when with the increment of the density values their relative stability also increase and instabile when it decreases. In some cases with the increment of the density values the stability values change in a not monotonous way, in these cases we can describe the stability of the whole pattern giving the stability character for each density interval.

\section{Recommended investigation methods}

- We can start from the number of individuals caught at stated intervals (or other observed density values). In case of continuous observation we can make the analysis using different time-scale summations too, but we can compare only anlyses prepared in the same way. At the analysis of the possible scale dependence it is practical to take into consideration the cycles by generations, years etc.

- From the neighbouring values we form pairs.

- We measure the absolute changes with the difference N2-N1, where we substract always the former value from the following one independently of the size.

- To express the relative change we calculate the ratio $2^{*}(\mathrm{~N} 2-\mathrm{N} 1) /(\mathrm{N} 2+\mathrm{N} 1)$. This indicates how does the absolute change between two times (or periods) compare with the average density during this change $((\mathrm{N} 2+\mathrm{N} 1) / 2)$.

- We can calculate these indices for all data pairs and represent them in the following manners:

a) absolute changes against the time

b) relative changes against the time

c) absolute changes against the average number of individuals

d) relative changes against the average number of individuals

e) absolute and relative changes against each other.

The $\mathbf{a}$ and $\mathbf{b}$ type figures are suitable to describe more precisely the phenological events and to interpret the relationship of generations. In the present study we do not deal with these. The figures $\mathbf{c}$ and $\mathbf{d}$ make visible the fact and mode of density dependence. The e type figure helps to understand more exactly the phenomena. The figures $\mathbf{c}, \mathbf{d}$ and e afford possibility not only to compare with one another (in all combination) the phenomena observed in different species, areas or years but to compare them directly using mathematical models, that was impossible till now using only the basic data. From the c and $\mathbf{d}$ type figures, obtained from the processing of great number of data, we can directly read (in case of the dynamics manifested in the figure) what could be the maximal extent of the change by unit of time after a given density value (number of individuals or frequency of individuals (density) - depending on the applied method). In our opinion this information (although it does not show the direction of change) could have an important role also in the practice of plant protection prognosis.

Processing appropriate number of data splitted by different time scales we can get such population dynamical analyses that promote the biological cognition of the species exceeding the phenological characteristics. Completing all these analyses for many species we have the possibility to classify the species based on the characteristics mentioned above, and so we can approach to the explanation of phenomena related to population dynamics. 
We can express the absolute and relative instability belonging to the given density values (or intervals) with the range or standard deviation of the adequate deviation values.

The stability character of the whole pattern we can read directly in the $\mathbf{c}$ and $\mathbf{d}$ type figures or in the representation of the values given before.

\section{Case studies}

To illustrate the conception presented above we present three dynamical patterns. In all cases we use two pairs of $\mathbf{c}$ and $\mathbf{d}$ type figures, with values calculated from real data and from the result of a model with similar behaviour to them. The y axis of the ctype figures shows the absolute changes, the $y$ axis of the $\mathbf{d}$ type figures shows the absolute changes. The $\mathrm{x}$ axis represents always the average number of individuals (it means the density values during the changing period). The data series are based on real field experiments, but we selected them on purpose to represent well the different simple basic patterns. In reality the majority of data series does not have such a clear-sighted form but they are mixtures of several patterns like these. The characteristic of a pattern may vary in time and space, on the other hand it is scale dependent. Making comparisons we must take all these into consideration. The presented models are used for emphasize the essentials, in themselves they are unsuitable for prediction. The patterns of the models show the behaviour of the extreme values from the pattern of the field data and these are what we examine also in case of field data, because these are of great importance in practical aspect, too. In the models the dynamics of increase and decrease is always symmetrical and usually this is the situation in reality too, but it is not necessary. Preparing analyses in order to become acquainted with the species we need much more data pairs than marked in these figures that calls the attention to the importance of the LTER examinations. All three examples are based on data from the national light trap system, data of 10 areas with "hot summer" summarized by ten days.

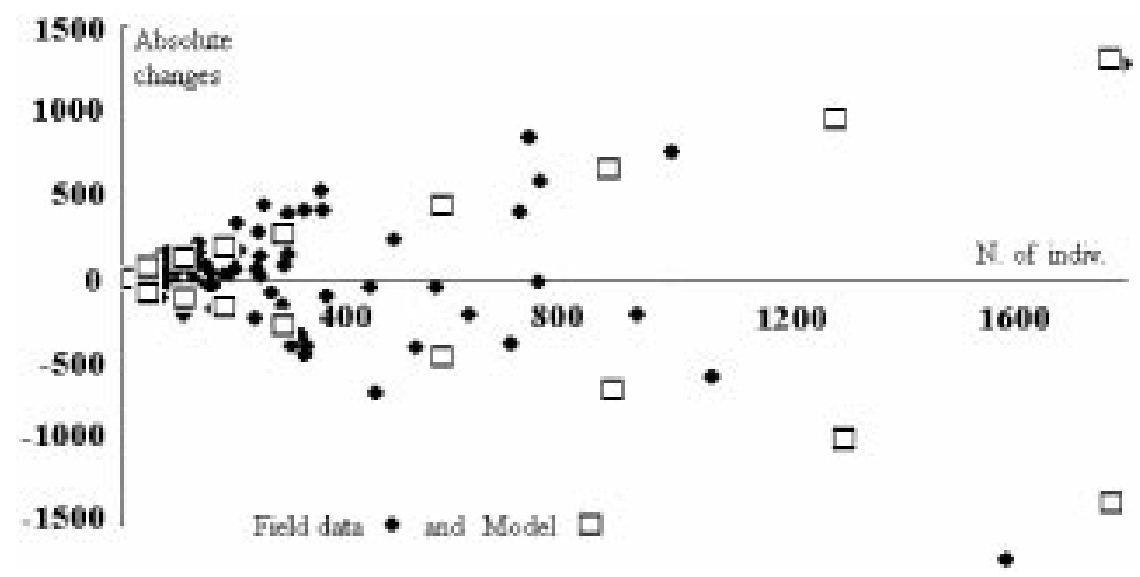

Fig. 1.1. Generations of Sitochroa verticalis between 1964 and 1969 
Example 1

Generations of Sitochroa verticalis between 1964 and 1969

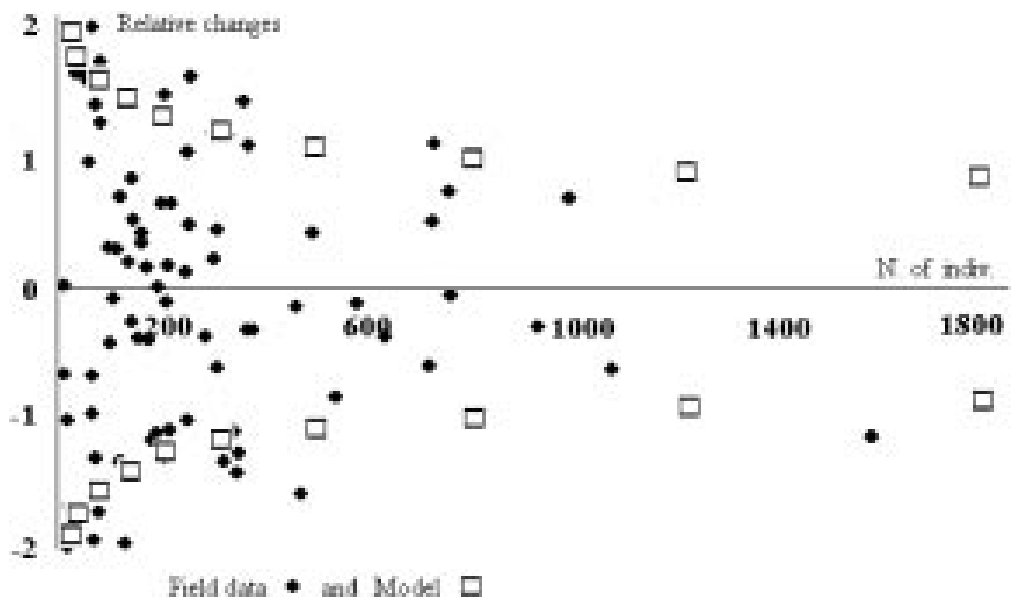

Fig. 1.2. Generations of Sitochroa verticalis between 1964 and 1969

The extreme values against the density follow a slowing increase regarding the absolute changes and slowing decrease regarding the relative ones. This behaviour is similar to models with the $n$th power, where $0<n<1$ (Figs. 1.1 and 1.2)

Example 2

The second non-gradational generations of Evergestis extimalis between 1964 and 1969

Concerning the absolute changes the extreme values increase until a maximal density and then they decrease, the relative changes have an accelerating increase. The applied model: $N_{\mathrm{t}}=N_{\mathrm{t}-1}+a N_{\mathrm{t}-1}-b N_{\mathrm{t}-1}{ }^{c}$, where $a>1,0<b<1, c>1$.

This is similar to a logistic model (Figs. 2.1 and 2.2).

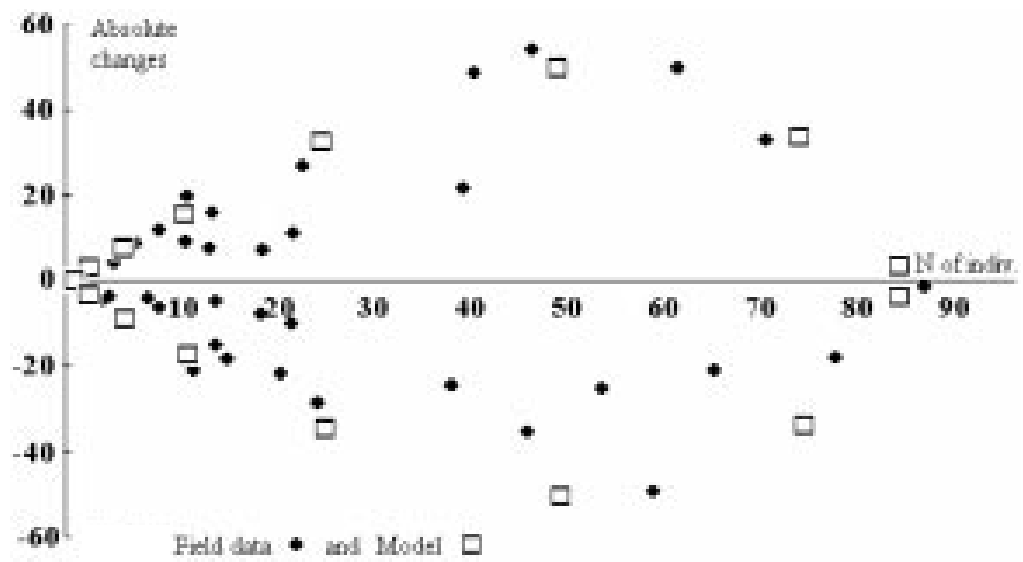

Fig. 2.1. The second non-gradational generations of Evergestis extimalis between 1964 and 1969 


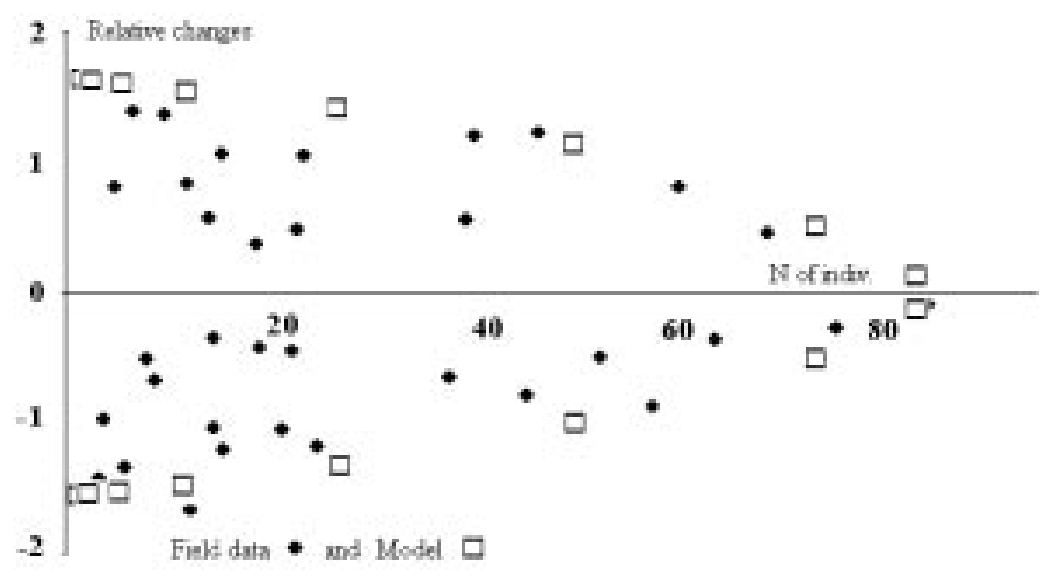

Fig. 2.2. The second non-gradational generations of Evergestis extimalis between 1964 and 1969

Example 3

The second generations of Etiella zinkenella between 1963 and 1969

Concerning the absolute changes the extreme values have a linear increase, the relative changes show a constant form.

The applied model: $N_{\mathrm{t}}=N_{\mathrm{t}-1}+a N_{\mathrm{t}-1}$, where $a>1$.

This is similar to the exponential model (Figs. 3.1 and 3.2).
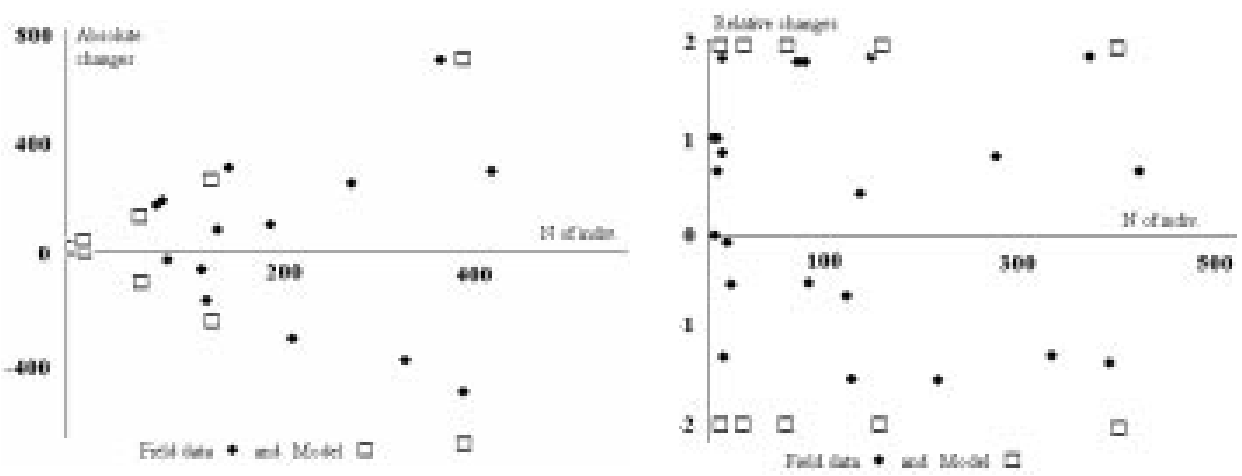

Figs 3.1 and 3.2. The second generations of Etiella zinkenella between 1963 and 1969

\section{Literature}

Benedek, P., Deli, O. and Jászai, J. (1969): A növényvédelmi előrejelzés üzemi módszerei (Practical methods of plant protection prognosis). MÉM, Budapest.

Benedek, P., Surján, J. and Fésűs, I. (1974): Növényvédelmi előrejelzés (Plant protection prognosis). Mezőgazdasági Kiadó, Budapest. 
Den Boer, P. J. (1986): Density dependence and the stabilization of animal numbers. Oecologia 69, 507-512. Huffaker, C. B. (1984): Ecological Entomology. A Wiley-Interscience Publication, New York.

Juhász-Nagy, P. and Vida, G. (1978): Szupraindividuális organizáció (Supraindividual organisation). In: Csaba, Gy. (ed.): A biológiai szabályozás (Biological regulations). Medicina Könyvkiadó, Budapest.

Manninger, G. A. (1968): Kártevők prognózisa és szignalizatiója (Prognosis and signalisation of pests). In: Ubrizsy, G. (ed.): Növényvédelmi enciklopédia (Plant protection encyclopedia). Mezőgazdasági Kiadó, Budapest.

May, R. M. (1973): Stability and Complexity in Model Ecosystems. Princeton University Press, Princeton.

Maynard Smith, J. and Slatkin, M. (1973): The stability of predator-prey systems. Ecology 54, 384-391.

Nowinszky, L. (ed.): (1994): Light trapping of insects influenced by abiotic factors I. Savaria University Press, Szombathely.

Nowinszky, L. (ed.): (1997): Light trapping of insects influenced by abiotic factors II. Savaria University Press, Szombathely.

Vekerdi, L. (1978): A szabályozás alapelvei (Principles of regulation). In: Csaba, Gy. (ed): A biológiai szabályozás (Biological regulations). Medicina Könyvkiadó, Budapest. 